\title{
Evaluation of the Relationship between Cervical Intraepithelial Neoplasia Grades and Connexin 43
}

\author{
Havva Erdem ${ }^{1}$, Mürüvvet Akçay Çelik ${ }^{1}$ \\ ${ }^{1}$ Ordu University Medical Faculty, Department of Pathology, Ordu, Turkey \\ Received: 3 August 2017 Accepted: 15 November 2017, Published online: 28 December 2017 \\ (C) Ordu University Institute of Health Sciences, Turkey, 2017
}

\begin{abstract}
Objective: Cervical intraepithelial neoplasia (CIN) is a premalign cervical disease. The microscopic features of CIN indicates an alteration leading to dedifferentiation and loss of maturation in the squamous epithelium. Disruption of connexins are frequently reported in malignant cell lines. Here, it is aimed to show the relationship between the dysplasia grades and connexin.

Methods: 79 cases were included in the study who were referred to the pathology department between 2014 and 2015 and who had CIN (grade 1,2,3). Sections of 3 micrometer thickness were taken from the paraffin blocks of the uterus on the polylysine slide. $\mathrm{Cx} 43$ antibody with $\mathrm{ABC}$ tecnique were performed to these sections. Staining cells were defined as positive. The cases were graded according to the intensity of the staining.

Results: The distribution of 79 dysplastic cases was as follows. 41 of these cases had CIN 1. The average age of these women was 44.93. 16 women were diagnosed with CIN2. The average age of these women was 42.06. 22 women were diagnosed with CIN 3 . The average age of the women was 48.87 .

Conclusion: In this study, complete loss of $\mathrm{Cx} 43$ expression was observed in all dysplastic cervical cases. Key words: Cervical intraepithelial neoplasia, degree of dysplasia, Cx43
\end{abstract}

Address for correspondence/reprints:

Havva Erdem

Telephone number: +904522250185

E-mail: drhavvaerdem@gmail.com

DOI: $10.19127 / \mathrm{mbsjohs.332613}$

\section{Introduction}

Cervical cancer is seen all over the world, after breast and colorectal cancers in women. It is still the second most frequent cancer in developing countries, in the developed countries frequency ranks has decreased to the 10th from sixth with help of the main screening programs (Parkin et al., 2005; Ferlay et al., 2010).

Cervical intraepithelial neoplasia (CIN) is a premalign cervical disease, also called cervical squamous intraepithelial lesion (LSIL). The microscopic features of CIN indicate an alteration leading to dedifferentiation and loss of maturation in the squamous epithelium; which is characterized by proliferation abnormalities in the basal and parabasal layers (Atasü and Aydınl1, 1996).

Gap junctions (GJ) play an important role in the proliferation, differentiation, migration and other cellular functions of cells, and homeostasis and tumor suppression. GJs play a role in intercellular communication in many tissues and organs with 
epithelium, muscle and nerve tissues (Hong and Lim, 2008).

The connexins (Cx's) are structural precursors of GJs. Cx's are widely distributed in all mammalian cells. Recent studies have shown that Cx's can affect cellular homeostatic balance independently of intercellular communication (Ferlay et al., 2010).

There are alternative mechanisms that can sustain tissue function if one of the molecules of the $\mathrm{Cx}$ family in many cell types is mutated or not synthesized. However, in numerous studies conducted in recent years, mutations in genes encoding $\mathrm{Cx}$ proteins have been found to result in severe and chronic illnesses. In many cases, singlepoint mutations cause dramatic consequences due to the insufficient amount of $\mathrm{Cx}$ and the lack of internalization (Atasü and Aydınlı, 1996). The Cx classification is based on two systems. The first refers to the molecular weight predicted from the cDNA sequence. For example, Cx 26, Cx 32, Cx 43 refer to molecular weights of $32 \mathrm{kDa}$ and $43 \mathrm{kDa}$, respectively (Beyer et al., 1987).

Although the presence of $\mathrm{Cx}$ is unknown, it has recently been shown that these proteins are superimposed on cell and tissue proliferation. Together with these studies, the values of $\mathrm{Cx}$ in cell and tissue types were tried to be revealed (Atasü and Aydınl1, 1996).

There are different results in the literature showing the relation of $\mathrm{cx} 43$ with the dysplasia grades. We aimed to investigate this relationship in this study.

\section{Methods}

79 cases were included in the study who were referred to the pathology department between 2014 and 2015. In this cases had CIN grade 1, 2 and 3.

Sections of 3 micrometer thickness were taken from the paraffin blocks of the uterus on the polylysine slide. $\mathrm{Cx} 43$ antibody with $\mathrm{ABC}$ tecnique were performed to these sections.

\section{Immunohistochemistry}

The sections were held in the $60^{\circ} \mathrm{C}$ for 1 hour then were passed through xylol and alcohol steps. Tissue sections were incubated in $3 \%$ hydrogen peroxide $(\mathrm{H} 2 \mathrm{O} 2)$ for 10 minutes to remove the endogenous peroxidase and then were washed in distilled water for 5 minutes. Antigen was retrieved through retrieval step. Immunohistochemical staining was performed with Avidin-Biotin Peroxidase Complex (ABC) technique. The antigen was washed in PBS after the retrieval protocol.
Primer antibody $\mathrm{Cx} 43$ (dilution ratio 1: 200) was applied. The sections were then plunged into AEC (3-amino-9-ethylcarbazole) chromogen substrate (10 minutes), washed with water, stained with hematoxylin (3 minutes) and covered with mounting medium. The stained sections were examined with a Nikon eclipse Niu microscope and photos were taken. Immunohistochemically stained preparations were examined. Cells showing staining were evaluated as positive. It was noticed that it was stained in endocervical glands and that there was no staining in the squamous epithelium (Fig. 1-3).

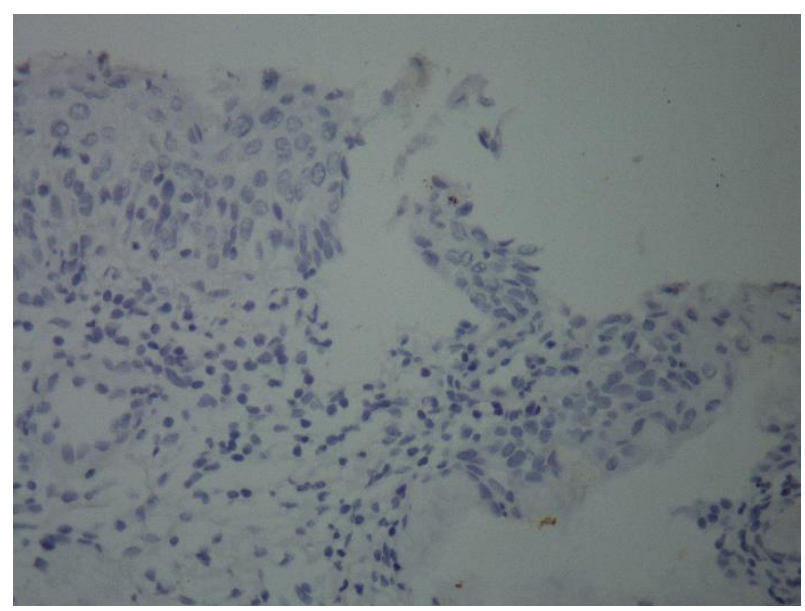

Figure 1. No staining in the presence of CIN-3 (Cx43x400)

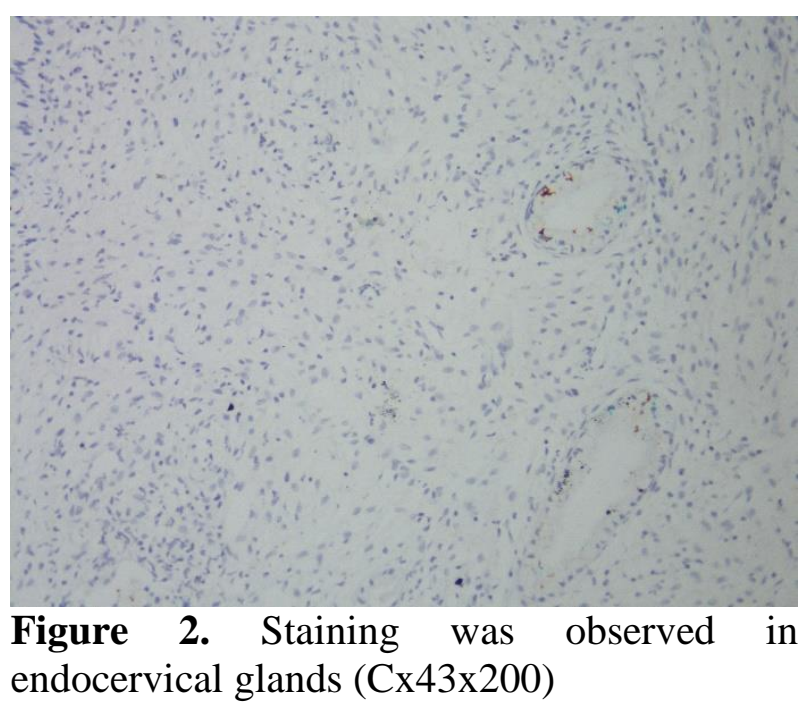




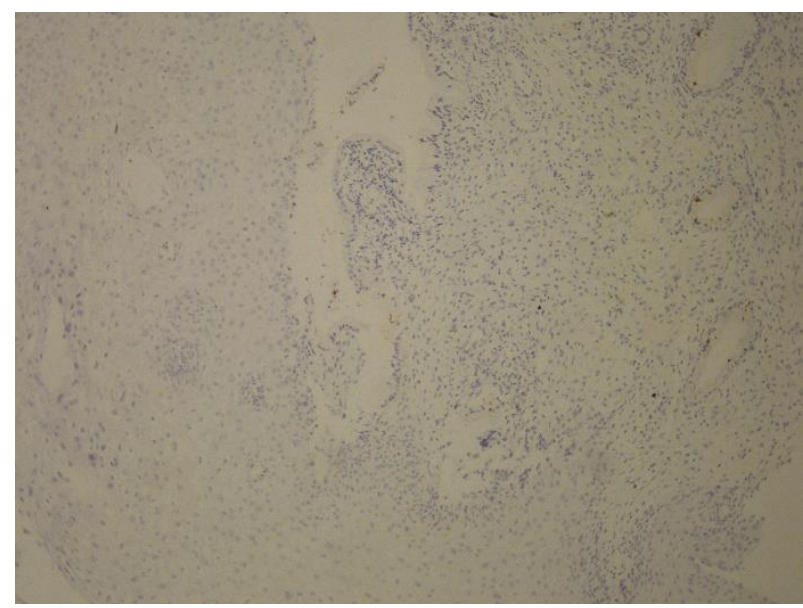

Figure 3. No staining in $\mathrm{CIN}-1$ epithelium, there is a weak staining in the endocervical epithelium (Cx43x100).

\section{Statistical Analysis}

Descriptive values that measured in the study are shown as mean, minimum, and maximum.

\section{Results}

41 of these cases were diagnosed with CIN 1. The average age of these women was 44.93. The ages were ranged between 31 to 66 years. 16 women were diagnosed with CIN 2. The average age of these women was 42.06 and the ages were ranged between 28 to 65 . 22 women were diagnosed with CIN 3. The average age of the women was 48.87 and the ages were ranged between 32 to 63 years.

CIN1, CIN2, and CIN3 were found to have grade 0 (negative) in staining with $\mathrm{Cx} 43$. Positive staining was observed in endocervical glands in all cases. There was no meaningful relationship between displasia levels and staining. Since dysplastic areas were stained negative with $\mathrm{Cx} 43$, they could not be evaluated statistically according to grades (table-1).

Table-1. Cx 43 staining results in dysplastic epitheliium according to grades

\begin{tabular}{rlccc}
\multirow{2}{*}{$\begin{array}{c}\text { CIN } \\
\text { grades }\end{array}$} & \multirow{2}{*}{ Number } & \multicolumn{2}{c}{ Cx 43 stain } & \\
\cline { 3 - 4 } & & Negative & Positive & Total \\
\hline I & 41 & 41 & 0 & 41 \\
II & 16 & 16 & 0 & 16 \\
III & 22 & 22 & 0 & 22 \\
Total & & & & 79 \\
\hline
\end{tabular}

\section{Discussion}

Some Cx's are very specific and are expressed in many tissues. One of them, $\mathrm{Cx} 43$ has been reported to be expressed in 35\% of the excess tissue (Beyer et al., 1995; el Aoumari et al., 1990).

The loss of cell junctional communication (GJIC) is due to abnormal proliferation and increased neoplastic phenotype. Several human tumors, including HeLa and cervical carcinoma line, have been reported to be inadequate for expression of the gap junction protein $\mathrm{Cx} 43$ and GJIC. To determine whether this is an early event in the carcinogenesis, King et al. screen a series of cervical biopsies using immunohistochemical techniques. They showed that there was a large reduction in $\mathrm{Cx} 43$ expression in the dysplasia regions as a result of the study (King et al., 2000).

There is extensive literature knowledge that suggests that these junctions are associated with cellular growth control and tissue differentiation, and tumor suppressor. It has been suggested that impairment of intracellular communication of GJ protein expression, abnormal cytoplasmic localization. Gap junctions are important events in carcinogenesis, invasion and metastasis (Nicolson et al.,1988; Carystinos et al., 2001). However, the role of Cx's in carcinogenesis and metastasis is controversial, since it is still unclear whether $\mathrm{Cx}$ expression is required for invasion and metastasis (Carystinos et al., 2001).

In a study by Bišanin et al., Cx43 expression was reported to be high in high grade dysplastic adenomas $(p=0.047)$, large adenomas $(p=0.015)$ and villous adenomas $(\mathrm{p}=0.02)$ (Bišćanin et al., 2016). In adenomas, Cx 43 expression was reported to be no differences between the degree of dysplasia $(\mathrm{p}=0.87)$ (Bišćanin et al., 2016).

In this study, $\mathrm{Cx} 43$ expression was not observed in the dysplastic epithelium so there was no change in expression according to the degree of dysplasia.

In a study carried out by Hieber et al., carotenoids have been shown to increase $\mathrm{Cx} 43$ expression in message and protein levels in suprabasal layers of human keratinocytes in human and mouse fibroblasts and in organotypic cultures (Hieber et al., 2000).

In a study has been reported to be a significant observation in terms of apparent suspension formation in the growth of human tumor cells (Sutherland and Bennett, 1984). Thus, Cx43 expression strongly inhibits the in vitro marker of malignancy (Sutherland and Bennett, 1984). 
Expression of $\mathrm{Cx} 43$ in human carcinoma cells has been shown to decrease both in vivo and in vitro (Sutherland and Bennett, 1984; Nicolson et al., 1988; King et al., 2000; Hieber et al., 2000; Carystinos et al., 2001; King et al., 2002; Bišćanin et al., 2016).

Again, in a study on connexins and cancer, dysplastic epithelium staining was observed, as well as dysplasia-free glandular epithelium staining. There was no difference between staining grade and dysplasia grade (Bertram, 2004).

There have been recent publications showing that $\mathrm{Cx} 43$ was negative or weakly positive in poorly differentiated carcinoma (Puzzo et al., 2016).

In the study performed by Wilgenbus et al., benign tumors and some malign tumors were studied. They reported that renal and breast cancer and sarcomas showed a significant decrease in gapjunction proteins as opposed to normal tissue (Wilgenbus et al., 1992).

Tada et al. observed that $\mathrm{Cx}$ expression was weak in BCC and SCC, and expression was absent in ecrine and apocrine glands (Tada and Hashimoto, 1997).

In a study by Schneider et al., Cx 43 reported cases of basal, parabasal, and middle-layer connexin (Schneider et al., 2002).

In a study on cervical dysplasia was reported that Cx 43 expression is very low in normal cervix $(100 \%)$ but, Cx 43 expression in low-grade squamous intraepithelial lesions $(64 \%)$ increased in the parabasal cells. As well as loss in staining (47\%), weak-full-thickness Cx 43 staining (53\%) were observed in high-grade squamous intraepithelial lesions. In the same study, it was noted that $\mathrm{Cx}$ expression disappeared as dysplasia increased (Hagemann et al., 2012).

In this study, it was seen that there was no staining in all the layers of the dysplastic epithelium. When evaluated according to dysplasia grades, it was also seen that there was a loss of full staining. Weak staining of endocervical glands was evaluated as an internal control. Normal cervix epithelium could not be evaluated because it was not included in this study. therefore, normal epithelium and dysplasia epithelium could not be compared.

\section{Conclusion}

In this study, no staining with $\mathrm{Cx} 43$ was observed in dysplastic surface epithelium, compared with normal endocervical gland epithelium. This condition is thought to be related to the reduce of gap junction protein in dysplastic epithelium. However, no difference was found between dysplasia grade and loss of expression

Ethics Committee Approval: Ethics committee approval was received for this study from in Clinical Research Ethics Committee of ORDU University.

Peer-review: Externally peer-reviewed.

Author Contributions: Concept - H. E., M. A. Ç.; Design H. E., M. A. Ç.; Supervision- H. E., M. A. Ç.; Materials - H. E., M. A. Ç.; Data Collection and/or Processing - H. E., M. A. Ç.; Analysis and/or Interpretation - H.E.; Literature Review - H. E., M. A. Ç.; Writing H.E.; Critical Review - H.E.

Conflict of Interest: No conflict of interest was declared by the authors.

Financial Disclosure: The authors declared that this study hasn't received no financial support.

\section{References}

Atasü T, Aydınlı K. Jinekoloji ve obstetrik pratiğinde kolposkopi. Jinekolojik Onkoloji.1996; 12:182.

Bertram JS. Dietary carotenoids, connexins and cancer: what is the connection? Biochemical

Beyer EC, Davis LM, Saffitz JE, Veenstra RD, "Cardiac intercellular communication: consequences of connexin distribution and diversity," Brazilian Journal of Medical and Biological Research.1995; 28(4):415-425.

Beyer EC, Paul DL, Goodenough DA: Connexin 43: A protein from rat heart homologous to a gap junction protein from liver. J Cell Biol. 1987; 105: 2621-2629.

Bišćanin A, Ljubičić N, Boban M, Baličević D, Pavić I, Bišćanin MM et al. Cx43 expression in colonic adenomas and surrounding mucosa is a marker of malignant potential. Anticancer Research. 2016(36) 10 ;5437-5442.

Carystinos GD, Bier A, Batist G. "The role of connexinmediated cell-cell communication in breast cancer metastasis," Journal of Mammary Gland Biology and Neoplasia.2001;(6)4;431440.

El aoumari a, Fromaget C, Dupont E, Reggio H, Durbec P, Briand JP et al., "Conservation of a cytoplasmic carboxy-terminal domain of connexin 43, a gap junctional protein, in mammal heart and brain," The Journal of Membrane Biology.1990;115(3):229-240. 
Ferlay J, Shin HR, Bray F, Forman D, Mathers C, Parkin DM. Estimates of world wide burden of cancer in 2008: Globocan 2008. Int J Cancer. 2010;127(12): 2893-917.

Hagemann IS, Pasha TL, Roberts SA, Yum SW, Zhang PJ. Aberrant connexin 43 and 26 expression in cervical dysplasia. Analytical and Quantitative Cytology and Histology. 2012; 34(1):28-40.

Hieber AD, King TJ, Morioka S, Fukushima LH, Franke AA, Bertram JS. Comparative effects of all-trans beta-carotene vs. 9-cis beta-carotene on carcinogen-induced neoplastic transformation and connexin 43 expression in murine 10T1/2 cells and on the differentiation of human keratinocytes. Nutr. Cancer. 2000; 37:234-244.

Hong R, Lim SC. Pathological significance of connexin 26 expression in colorectal adenocarcinoma. Oncology Reports. 2008; 19: 913-919.

King TJ, Fukushima LH, Hieber AD, Shimabukuro KA, Sakr WA, Bertram JS. Reduced levels of connexin 43 in cervical dysplasia: inducible expression in a cervical carcinoma cell line decreases neoplastic potential with implications for tumor progression. Carcinogenesis.2000;(21)6:1097-1109.

King, TJ, Fukushima, LH, Yasui Y, Lampe P.D, Bertram JS. Inducible expression of the gap junction protein connexin 43 decreases the neoplastic potential of HT-1080 human fibrosarcoma cells in vitro and in vivo Mol. Carcinog. 2002;35:29-41.
Nicolson GL, Dulski KM, Trosko JE. "Loss of intercellular junctional communication correlates with metastatic potential in mammary adenocarcinoma cells," Proceedings of the National Academy of Sciences of the United States of America.1988;(85)2;473-476.

Parkin DM, Bray F, Ferlay J, Pisani P. Global cancerstatistics, 2002. CA Cancer J Clin. 2005;55(2):74108.

Puzzo L, Caltabiano R, Parenti R, Trapasso S, Allegra E. Connexin 43 (Cx43) Expression in Laryngeal Squamous Cell Carcinomas: Preliminary Data on Its Possible Prognostic Role. Head Neck Pathol. 2016;10(3):292-7.

Schneider B, Teschner M, Sudermann T, Pikula B, Lautermann J. Expression of gap junction proteins (connexin 26, 30, 32, 43) in normal mucosa, hyperkeratosis and carcinoma of the human larynx. ORL J Otorhinolaryngol Relat Spec. 2002;64(5):324-9.

Society Transactions.2004;32(6): 985-9.

Sutherland BM, Bennett PV. Transformation of human cells by DNA transfection. Cancer Res. 1984;44: 2769-2772.

Tada J, Hashimoto K. Ultrastructural localization of gap junction protein connexin 43 in normal human skin, basal cell carcinoma, and squamous cell carcinoma. J Cutan Pathol. 1997 ;24(10):628-35.

Wilgenbus KK, Kirkpatrick CJ, Knuechel R, Willecke K, Traub O. Expression of Cx26, Cx32 and $\mathrm{Cx} 43$ gap junction proteins in normal and neoplastic human tissues. Int $\mathbf{J}$ Cancer. 1992;51(4):522-9. 